ID_INVESTIGACIONES

\title{
PARAJES COSTEROS, TURISMO Y PAISAJES CULTURALES EN URUGUAY
}

\author{
Arq. Ingrid Roche \\ Facultad de Arquitectura - Universidad de la República.
}

\section{RESUMEN}

La evolución de las áreas costeras sureñas, confirma su destino, oficialmente fomentado desde 1920, como sitios privilegiados para vacaciones, y atractores turísticos crecientes a nivel regional. El análisis interpretativo de las formas de ocupación y valorización de geografías convertidas en paisajes culturales por habitantes y visitantes incluye: urbanizaciones turísticas consolidadas de significativa diversidad morfológica y socio-histórica, atractivos poblados de pescadores por su rusticidad y trazados balnearios planificados "irregulares o espontáneos". Alternan con parques forestados como camping en zonas privilegiadas, extensos espacios apenas colonizados, cuencas lagunares de abundantes recursos, áreas de dinámicas naturales activas y rurales. Propender a relaciones respetuosas con la naturaleza, en territorios cuasi virginales, por despoblados, serían objetivos alcanzables.

La legislación y normativas de ordenación en elaboración o recientes, sugieren instrumentos de desarrollo sin afectar a los recursos, considerando su vulnerabilidad. Extraer conclusiones cautelares, evitando depredaciones futuras, requiere estudios históricamente fundamentados y visiones contemporáneas sobre compatibilidad entre turismo y naturaleza.

Palabras claves: territorio, recursos, planificación, ambiente 


\section{ID INVESTIGACIONES}

\section{ABSTRACT}

The Uruguayan Southern coastal areas have evolved to become privileged vacation sites, attracting increasingly regional tourism, thus fulfilling the purpose officially promoted since 1920 . The interpretative analysis of the modes of land occupancy and appreciation of the cultural landscapes by inhabitants and tourists will include: consolidated tourist urbanizations with diverse morphologies and social histories, charming rustic fishing villages, and seaside resorts with irregular layouts. The coastal area comprises alternating forest parks with camping sites, vast barely occupied fields, fertile lake basins, dynamic natural areas, and agricultural lands. The respectful relationship between people and nature in these vastly unpopulated somewhat virgin territories is a fairly attainable goal. The recent regulations on territorial planning point towards development instruments which take the vulnerabilities into consideration to avoid jeopardising natural resources. The design of precautionary conclusions to avoid future depredation requires historically based research and contemporary approaches to compatibility among natural attractions and tourism.

Keywords: territory, environment, resources, planning

\section{INTRODUCCIÓN}

El análisis de la evolución de los poblados en áreas costeras, como destinos de recreación activa, vacaciones y recorridos turísticos, su compatibilidad con los recursos paisajísticos naturales que los originan y las expectativas sociales, es de singular pertinencia para el caso uruguayo. Con la creciente afluencia de visitantes en el extenso borde de Rocha se presentan puntos y áreas singulares de paisaje y varias modalidades de asentamientos y ocupaciones. Incluye urbanizaciones turísticas consolidadas, poblados de pescadores 


\section{ID_INVESTIGACIONES}

convertidos en lugares atractivos por su rusticidad, trazados balnearios, parques forestados con camping en zonas privilegiadas. Entre ellos, predominan espacios libres apenas colonizados, micro-cuencas con abundantes recursos, lagunas, áreas de dinámicas naturales activas, establecimientos rurales y otros de destino incierto.

Siendo incipiente su valoración y protección, y encontrándose planteada la posibilidad de nuevas infraestructuras en estas zonas, conviene revisar la historia de estos parajes costeros. Su evolución sin planes o proyectos generales de inicio, o con prefiguraciones parciales; con algunas intervenciones y planes de regularización en el proceso, deberá cotejarse con la legislación y normativas de ordenamiento, muy recientes y sujetas a fuerte debate. EI objetivo es que las nuevas ocupaciones previsibles, puedan provocar la recomendable puesta en valor, y no una indeseada degradación del paisaje.

Nuestro propósito es aportar visiones para que los procesos de ordenación y gestión de territorios con altas potencialidades y riesgos por su extraordinaria calidad ambiental y cuasi-virginidad, sean acordes a los conocimientos y expectativas contemporáneas: respeto ambiental y beneficio social. Investigar las relaciones entre condiciones geo-topográficas, ámbitos bio-caracterizados, formas de ocupación, fraccionamientos, morfologías y tipologías, sus adaptaciones y/o procesos de deterioro respecto a los recursos paisajísticos.

El enfoque hipotético es que la costa oceánica de Rocha es en conjunto un bien preciado a conservar y potenciar para diversas modalidades de recreación activa y turismo de baja intensidad o de naturaleza. La oportunidad de mantener la calidad ambiental y paisajística, con el espectro posible en cuanto a normativas para fraccionamientos, formas de propiedad, ocupación del suelo, edificación y establecimiento de medidas estrictas de manejo en cuanto a usos y tratamiento de efluentes, aún está abierta. Se parte de la premisa de que el conocimiento y disfrute social de estos recursos relevantes, debiera implicar 


\section{ID_INVESTIGACIONES}

modalidades vacacionales inclusivas socialmente y no exclusivamente de alto nivel, como alguna norma sugiere. Atender a demandas de diversos niveles de confort, camping organizados, hostales, cabañas en propiedad o alquiler, hotelería de diversa categoría, según la variedad actual y siempre a favor de la naturalidad del paisaje, debiera ser el objetivo.

El análisis documentado y comparado de casos en el ámbito nacional, interpretando las formas de ocupación y procesos evolutivos de los poblados turísticos, los trazados, implantaciones y tipologías, las características de los paisajes culturales creados, permitiría detectar afectaciones, fragilidades a considerar y ejemplos positivos o modélicos.

$\mathrm{Y}$ así, efectuar algunas proyecciones y acotamientos, aunque tendientes a lo utópico, cercanos a lo posible en su dimensión económica. Si bien el fenómeno turístico integra tendencias crecientes a nivel mundial y se le refiere como industria que se transforma y globaliza, las actividades vacacionales en Rocha son bastante marginales a ese proceso. Proyectar priorizando intereses públicos, son objetivos declarados, legislados y alcanzables, aprovechando nuestras aparentes desventajas de localización periférica. Valorizar los paisajes culturales creados por habitantes permanentes y cíclicos, en el marco de la mayor naturalidad, sería la perspectiva deseable.

En Uruguay la importancia de las modalidades de conformación histórica como constituyentes del carácter, valor o imagen a proteger, de áreas edificadas privilegiadas por homogeneidad, ha sido socializado, oficializado $y$ patrimonializado muy recientemente. El reconocimiento de áreas caracterizadas, preconizado desde los años 80, y apenas extendido el concepto, continúa sin abarcar la valoración escénica, la calidad ambiental e identitaria de los patrimonios naturales o paisajísticos. Los del trabajo industrial, rural o de los parajes poco antropizados, como los turísticos o vacacionales, son aún poco reconocidos en su estética y valores conformadores de paisajes 


\section{ID_INVESTIGACIONES}

culturales. Estos productos de una actividad del siglo XX, genéricamente de factura arquitectónica privada, doméstica o comercial y urbanística no oficial, irregular o aparentemente desregulada, no han sido incorporados como característicos y de interés objetivable. Aunque expresada en el imaginario colectivo y la actuación de decisores, proyectistas formales o espontáneos del territorio, la urbanización de vacaciones, ha protagonizado escasos análisis académicos. ${ }^{1}$

\section{DESPOBLADO, NOMADISMO Y ÉXODOS EN LA HISTORIA URUGUAYA}

Fueron muy escasas en esta banda oriental, las urbanizaciones anteriores a 1800, y durante largo período, sólo aldeas, puertos o poblados junto a las fortificaciones de Colonia del Sacramento portuguesa, la Bahía de Montevideo (con cuadrícula negadora de su carácter), en zonas fronterizas móviles con el imperio luso-brasileño o los puertos más abrigados del Río Uruguay. Las costeras, contactos permanentes entre ambas bandas, lugares de abastecimiento y comercialización para navíos de costa o ultramar, carretas, y ya finalizando el siglo XIX, adjuntas a las joyas edilicias del ferrocarril, no dejaban de ser pequeños parajes. Intercambiadores de productos del ganado, insumos para manufacturas, materiales de construcción y subsistencia y algunos suntuarios, muy pocos evolucionaron a poblados perdurables. Tanto la campiña, vista como territorio agreste, de vastas soledades y de trabajo rudo para los criollos y gauchos, como los arroyos, ríos y mares eran amenazantes, en relación a las imágenes referenciales europeas. Además de los puertos coloniales, no había otras ciudades costeras, ni las hubo como tales hasta muy avanzado el siglo XX. Maldonado, Rocha y otras poblaciones interiores cercanas al litoral se comunicaban por navíos, pero apenas generaron peque-

${ }^{1}$ Revistas Elarqa, (1991) Nos. 1 y 5; 2001, No 41. Editorial 2 Puntos, Montevideo, son de las poças publicaciones que lo abordan. 


\section{ID_INVESTIGACIONES}

ños núcleos de casillas entre arenales en sus bahías expuestas a los vientos del Océano.

Con rasgos poco precisos, por simplificación, o desprecio documental de los historiadores patricios, ha sido recientemente que se conoce que éstos fueron los antiguos territorios de pequeños grupos indígenas semi-nómades ${ }^{2}$. Los arqueólogos han rescatado lo del prefijo semi y los parajes costeros como lugares privilegiados de pesca y caza, donde se asentaban cíclicamente, e incluso cultivaban y desarrollaban artesanías. Los primeros poblados costeros, fueron puntos de acceso de los colonizadores, asentamientos jesuíticos, y otros de convivencia soldadesca de variados orígenes, los atracaderos para el mítico ingreso del ganado y su salida hacia otras tierras y guerras. El seminomadismo del indio y del gaucho a lo largo del territorio, y en las costas la piratería, vaquerías, conquistas desde el mar, naufragios, invasiones y luchas por la primacía portuaria y la circulación por los ríos, fueron constantes durante bastante más de tres siglos. Generaron rastros arqueológicos terrestres y subacuáticos y ciertos fantasmas en el imaginario citadino.

Apenas unos miles de europeos y criollos, de Canarias, los primeros, constituían sus habitantes en el siglo XIX, al ser la población indígena casi totalmente exterminada, o mestizada violentamente y desplazada hacia la campaña, o a los que serán países vecinos. El comercio de esclavos africanos, origen de algunas grandes fortunas, sí tuvo importante incidencia cultural y aunque subterránea por mucho tiempo, fue pródiga en dar origen a cultos, música y tradiciones. Desde empleos domésticos, trabajos en servicios o de soldados y policías, se incorporaron al patrimonio inmaterial hoy reconocido oficialmente. Durante el primer siglo independiente, signado por luchas supra-nacionales la población creció muy lentamente, las mujeres eran

${ }^{2}$ VIDART, D. y otros antropólogos han investigado sobre los pueblos indígenas originarios, los guaraníes de poblados jesuítas, y otros en sítios como los Cerritos de Indios en Rocha.Entrevistas 2009 www.socioespectacular. 


\section{ID_INVESTIGACIONES}

pocas, duras las condiciones e inseguridades. La campaña era territorio de gauchos, contrabandistas y ejércitos; sus propietarios, familias patricias o caudillos por apropiación o concesión, ni conocían sus límites y las regenteaban en gran parte desde las ciudades. Resulta significativo que el evento elegido oficialmente en 2011 para el Bicentenario, sea el Éxodo del Pueblo Oriental, liderado por el héroe nacional. Gente en su mayoría de escasos recursos, indios, zambos, criollos, pobladores rurales, dejaron el sitio a Montevideo y se desplazaron hacia el litoral del río Uruguay: el eje geográfico de lo que su Jefe concebía como las Provincias Unidas (con las hoy argentinas). José Gervasio Artigas, descendía de los primeros pobladores poseedores de estancias reales, fue soldado español y contrabandista en la frontera con Río Grande do Brasil antes de ser libertador y morir tras treinta años exilado en Paraguay. Aunque poco reconocidas, la traición de otros caudillos y la actuación de un influyente diplomático ${ }^{3}$ fueron decisivas.

Es después de los episodios modernizadores, especialmente la introducción del ferrocarril y el alambramiento ${ }^{4}$ de los campos a fines del S XIX y más en el siglo $\mathrm{XX}$, que empiezan a llegar los grandes contingentes inmigratorios de Europa. Esta población se afincó en el litoral muy fértil al Sudoeste y Oeste del país, en reducidas colonias agrícolas y de producción granjera, de artesanía de pequeña escala, en zonas de huertos y chacras de pueblos nuevos. La producción ganadera extensiva en grandes propiedades, característica del resto del territorio-pradera no atraía población, empezó tempranamente a rechazarla; esta peculiaridad signó fuertemente el futuro, identidad, cultura y costumbres nacionales. La industrialización sustitutiva que acompañó a las guerras mundiales, los importantes servicios estatistas y de bienestar urbano, promovidos por los gobiernos de la época y las malas condiciones de vida de los trabajadores rurales, los empujaron a las capitales departamentales y a la

${ }^{3}$ Lord Ponsomby, hábil diplomático inglês que también participo de la creación de Belgica.

${ }^{4}$ Delimitación obligatoria de propiedades, dispuesta por Gral. Presidente Latorre en 1875 


\section{ID_INVESTIGACIONES}

ciudad principal a buscar mejores perspectivas. Así, Uruguay fue el país de urbanización más temprana de América Latina, con modalidad radial de poblamiento y extracción de producción, hacia el puerto exportador y macrocefálico de Montevideo. La población en actividades no rurales, ya era francamente mayoritaria en los años sesenta y desde 1990 mayor al 90\%, con muy bajas densidades poblacionales en el campo y creciente concentración costera. Esta urbanización y la propagación de ideas liberales, anarquistas y socialistas, traídas por los inmigrantes, muchos españoles e italianos, y también del Este europeo, que lo convirtieron en país de escasa religiosidad, explican las bajas tasas de natalidad. (Barran, P. 2008). En el campo, las familias eran numerosas y asimismo en las clases altas, pero primó la austeridad de los inmigrantes y la formación de amplios sectores medios. Muchos empleados públicos y bancarios, integraron al imaginario la autoproclamada: Suiza de América o Montevideo: Tacita del Plata.

Pero en la crisis de los 60 , que intimistamente, rebeldemente, o poéticamente, describieron sus escritores y cantores ${ }^{5}$, esta sociedad que miraba tanto a Europa, descubrió sus pies enlodados en el barro del estiércol vacuno, las cañeras, arroceras y peonadas escondidas debajo de los expedientes. Los obreros fabriles de productos nacionales ya no pudieron competir con las tecnologías más avanzadas que la guerra generó. Al entrar en las agitaciones que desembocaron en dictaduras en todo el Cono Sur, se acentúa la desindustrialización y/o reconversión neoliberal y con éstas se inicia un éxodo poblacional de nuevos nómades, emigrantes hacia el exterior. Esta corriente, signada hasta 1985 por persecuciones político-gremiales masivas, de sectores desplazados laboralmente del mercado y desconformes con el proceso, se afianza y se convierte en estructural. Con efectos demográficos graves, implica a familias enteras de todos los sectores sociales, por períodos largos, incluyendo muchas con buena calificación educativa y/o laboral. Quizás por

${ }^{5}$ Onetti, J.C, Benedetti,M; Viglietti,D; Zitarrosa,A. los más conocidos 


\section{ID_INVESTIGACIONES}

aquellos y estos designios de localización, origen y circunstancias, se estimó un quinto de los uruguayos radicado fuera del país, 700.000 personas, a inicios del siglo XXI. En 2004 por primera vez, se invierten algunos saldos migratorios internos, la capital atrae menos población que los vecinos departamentos costeros de Canelones y Maldonado. Éstos crecieron principal y originalmente con las viviendas de segunda residencia, que los sectores medios pudieron adquirir en las "buenas épocas" y hoy albergan población estable. En 2009, la crisis en el Norte compensará un fenómeno que signó tan fuertemente nuestra historia de treinta años de éxodos expulsivos y los ingresantes son más que los que se van. ${ }^{6}$

\section{EL CONJUNTO COSTERO. IDENTIDADES Y PAISAJES CULTURALES}

Recogidos en publicaciones de promoción como Playas Uruguayas. Punta del Este de 1920, relatos de viajeros sobre animales traídos del desierto por un promotor para llegar a esa península, nos retrotraen a lo que fue el atractivo de sus paisajes agrestes. En sentido curiosamente sorprendente, los arenales de Rocha se encuentran actualmente en grandes extensiones, en similar grado de naturalidad y su principal balneario La Paloma y adyacencias tienen cinco mil habitantes estables y en verano, menos de veinte mil $^{7}$. Los gobiernos estatistas propiciaron tempranamente estas actividades turísticas, las promociones de hoteles, créditos a emprendimientos de sociedades de loteadores, coincidieron con períodos expansivos de las actividades de construcción. Aunque muy aferrados al centralismo montevideano, vieron en estos servicios, materializa-

\footnotetext{
${ }^{6}$ Pellegrino,A (2009) en www.ine,gub.uy. Facultad de Ciencias Sociales-UdelaR. Los datos de 2006 sacudieron con el hallazgo de tasas críticas de reposición demográfica. (menos de dos hijos). En 2009 por retornos, de población jubilada y/o desocupados de EEUU y España- se revierte el flujo migratorio negativo.

4640 habitantes (INE, Censo 2004, incluidas La Aguada, Costa Azul y Arachania) que aumenta a 17.000 en los meses de temporada estival. Cifras citadas por Gadino, I. 2010.
} 


\section{ID_INVESTIGACIONES}

dos en parques y otras acciones de embellecimiento ${ }^{8}$, fuentes de ingresos importantes y hasta un designio nacional, acentuando disparidades de condiciones entre interiores pobres y costas ricas (Tesis de Maestría MOTDU Crisci,G. 2009, Urruzola, J.P. 2006 y Musso,C. 2005).

Los procesos sociales sucintamente relatados, signados por la escasa población radicada, imprimieron a la Costa Sur, valores atractivos fuertes en la percepción de los demandantes potenciales del turismo de veraneo: los sectores rioplatenses urbanos con capacidad de ahorro. Que fueron numerosos por la bonanza de entreguerras, apreciaron la tranquilidad costera y crearon con caracteres bastante definidos: la arquitectura doméstica y vacacional, el paisaje natural-artificializado. La sucesión de playas, con algunos puntos geográficos excepcionales dieron lugar a morfologías y calidades de vida o recreación, calificables como de relativa naturalidad y escasa grandilocuencia. La ubicación periférica respecto a circuitos como los europeos mediterráneos, permitió tipos de turismo variados diferentes del masivo. Quienes aprecian estas características naturales para las vacaciones de veraneo, han sido conformadores de pasajes culturales urbanizados de muy baja densidad de ocupación, mayormente de viviendas individuales.

Solamente la capital Montevideo, signada tempranamente por su destino vacacional y en un tramo reconvertida a imagen de Copacabana, y algunos sectores de Punta del Este, adquirieron en los 60 caracteres de ciudades modernas. Siendo de entidad muy reducida respecto a otros destinos en el mundo, la actividad turística posee enorme importancia relativa para un país tan pequeño. En lo económico, altísima y segunda después de los rubros agropecuarios principales, y sobretodo por su impacto socio-cultural en la escasa población total residente. A un país de 3.500 .000 habitantes, aunque la mitad en esta área costera, se suman en el entorno de 500.000 visitantes si-

${ }^{8}$ Cita de carta del Presidente por dos períodos Batlle y Ordoñez, J. en $199 \mathrm{IHA}$ 


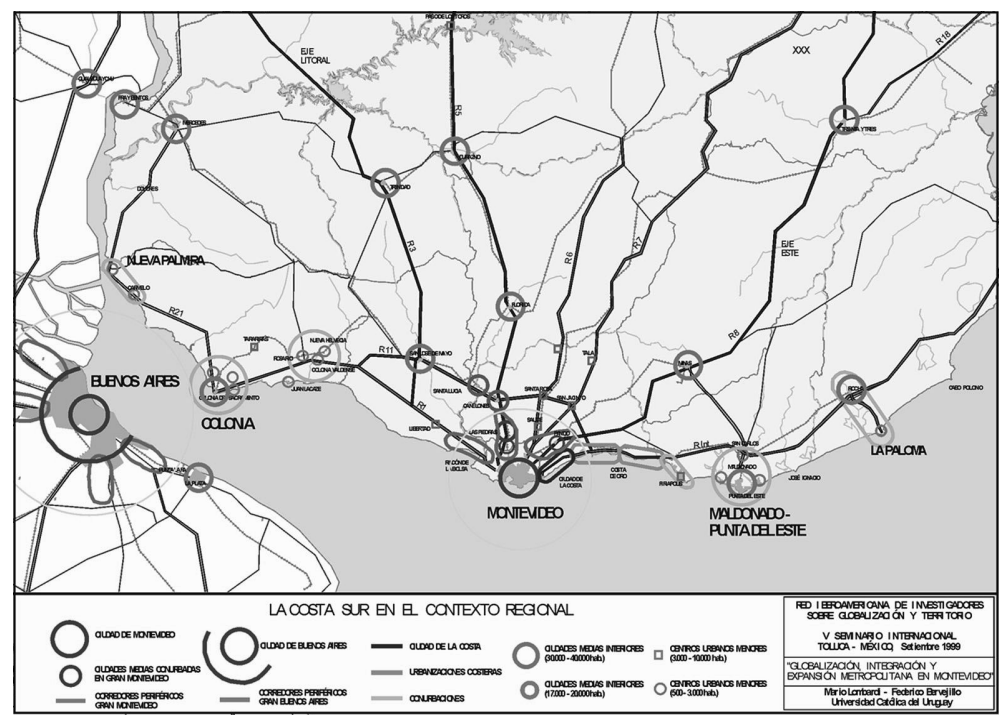

Costa Sur. Fuente Bervejillo,F; Lombardi,Toluca 1999

multáneos en verano (2 millones anuales) en un espacio reducido en ancho, y de traslados continuos en más de 650 km de longitud: una banda móvil ${ }^{9}$.

Siguiendo la metáfora de Drexler, $\mathrm{J}^{10}{ }^{10}$ en el borde de la gran penillanura o campo vacío, la geografía cultural costera, expresada al ritmo de las estaciones, produce temporarias densificaciones de los espacios públicos y privados. En cíclico vaivén se transforman e incorporan paisajes efímeros, identidades y valores diferentes de los estables constitutivos y se invisibilizan otros, perdiéndose o apenas manifestándose en ocasiones, fiestas, o documentos familiares, leyendas, y testimonios. Entre los veraneantes se incluyen nacionales del interior que se trasladan a disfrutar de los parajes cos-

${ }^{9}$ Crisci, G. (2009) Tesis de Maestría MOTDU-UdelaR. La Costa sur: Banda móvil

${ }^{10}$ Drexler, $J$. cantautor, en referencia a estrofas de "Un país con un nombre de un río"edición 2001 


\section{ID_INVESTIGACIONES}

teros, aunque su puntal fuerte por cantidad han sido: los turistas argentinos. Los atractivos geo-identitarios y culturales, hacen que el flujo de turistas se concentre en algunos nodos, en varios centenares de miles de personas, otorgándole vibraciones inéditas y se perciba como otro país. Es el caso de la principal ciudad turística Punta del Este que en verano se resignifica como cosmopolita, con acentos bonaerenses. Muy atrayente por su seguridad -en el contexto latinoamericano- para visitantes regionales de buen nivel económico; en temporada es casi inaccesible por el costo de sus servicios para la mayoría de nacionales, excepto algunos no residentes o que exploran el retorno ${ }^{11}$.

El afincamiento de trabajadores temporales o estables, principales protagonistas de la conurbación con Maldonado y San Carlos, ocupados en la actividad constructiva, inmobiliaria y conexas, se mantiene. Pero casi todos los servicios al consumo, son estacionarios y decaen, pasando: de la ciudad fantasía implantada a la ciudad fantasma.

Puede afirmarse que algunos de los valores identitarios en estos territorios de acogida al turismo, son comunes:

- las características geomorfológicas de pertenencia a un área climática templada, de encuentro de la penillanura pampeana, y acuática fluvial con el sistema lagunar atlántico del litoral brasileño con arcos de playas de arena, cabos y paisajes calmados poco poblados.

- en tendencia potente en el imaginario colectivo social regional, es percibida, como área apetecible respecto a calidades de vida y recreación, especialmente cuando el verano atrae hacia el río-mar, miradas y presencias reales y virtuales.

\footnotetext{
${ }^{11}$ Similar a la post-dictadura, órganos oficiales, facilitan las políticas de retorno y vinculación con los residentes externos.
} 


\section{ID_INVESTIGACIONES}

- presenta tensiones transversales por la relación de los poblados costeros con los interiores cercanos, donde por la temporalidad laboral e inexistencia de servicios residen los habitantes permanentes, así como con sus áreas rurales contiguas, pero no están exploradas estas vinculaciones en la agenda turística.

- es recorrible en itinerario casi lineal en menos de un día, parte del turismo bonaerense o brasileño con automóvil lo hace y hasta en bus, y podría analizarse como una entidad, bajo el concepto de paisaje cultural a ordenar y potenciar, con unidades paisajísticas contenidas.

Incluso Montevideo, destino turístico menos estacionario, experimenta una pulsación inversa en el estío; queda relativamente despoblada, servicios y empresas en general cerrados por licencias. Sólo las playas y ramblas, los buses hacia ellas, y las noches de espectáculos de carnaval, -con afluencia socialmente amplia- atraen a los que trabajan obligadamente, no comparten el imaginario generalizado o no pueden pagar los costos. ¿Dónde están los montevideanos? En los balnearios, particularmente en los que los sectores altos y extranacionales son minoritarios, no imponiendo los precios, o donde encuentran trabajo estacionalmente, y/o disfrutan sol y playa en diferentes formas y períodos. Familias que comparten primera y segunda residencia, miembros que viajan a trabajar y otros que se quedan, producen dinámicas peculiares del país turístico temporario. Muchos encuentran, en los parajes costeros de Rocha, poco desarrollados, atractivos cercanos a los paraísos perdidos $^{12}$ por su estado de cuasi-naturalidad.

\footnotetext{
${ }^{12}$ En referencia al concepto filosófico y al libro de Juan Pedro Bator Los Paraísos perdidos: la costa española.(2010). Editorial Saga Madrid.
} 


\section{ID I N VESTIGACIONES}

\section{EVOLUCIÓN DE LOS PRIMEROS BALNEARIOS}

Fuerte en el imaginario europeizante de los sectores urbanos pudientes ya a fines del siglo XIX, consolidado y extendido por muchos, en la época de bonanza general, el modelo balneario tuvo adaptaciones. Segundas residencias, de fin de semana y veraneo de familias nacionales y argentinas muy entrelazadas, a las que se accedía en carruajes, surgen situadas en parajes costeros próximos a las ciudades, especialmente Montevideo y Colonia. Aquí, la tradición hispánica de apropiación territorial y poblamiento, aunque presente, fue muy tardíamente consolidada y extendida. Las apenas diversificadas cuadrículas aplicadas casi sin obstáculos, salvo los desniveles de arroyos y antiguos caminos por los altos, en los territorios suavemente ondulados, adoptarán los bordes afrancesados y sucesivamente, los modelos paisajistas, el impulso modernizador californiano y variantes.

De los antiguos balnearios termales y de playa, transformaciones de barrios o continuaciones de la trama de la ciudad: el caso paradigmático es el de Montevideo mismo.

El desarrollo histórico de la ciudad portuaria, es excelente breviario y ejemplo de este devenir: las costas en la Bahía y Cerro y al S.E., Ramírez y Pocitos fueron zonas de saladeros, puertos, depósito de esclavos y de lavanderas, hasta que llega el estilo de las playas de baños. Atraídos por los baños de agua, de sol y recreación al aire libre, con temperaturas moderadas por vientos, los primeros veraneantes, comenzaron a hacer potente en el imaginario colectivo social (particularmente del bonaerense, con veranos calurosos) estas aptitudes. Desde inicios del siglo XX, la costa pasa a ser percibida como área apetecible respecto a calidades de vida y recreación, surgen el Parque urbano, el Hotel-casino, junto a las Rambla. En 1912 el extremo Carrasco, entre inaccesibles arenales, fue, por obra de visionarios fraccionadores, transformada en balneario de costosos chalets entre parques, con su Gran 
ID_I N VESTIG AC I O NES

Hotel y trazado ajardinado creado por paisajista francés. Ya según los modelos suburbanos hollywoodenses se completarán después los mas cercanos Malvín y Punta Gorda que eran (salvo en el borde costero) un conjunto de predios baldíos en los años 50 s.

La urbanización de Montevideo, con su Rambla característica (gran proyecto completado en los gloriosos años 30 ), se extiende en el vecino Canelones en suburbios de baja ocupación en una franja paralela al río-mar. En este territorio hoy metropolitano, los trazados ajardinados, rectangulares o de cuadrículas, chalets de diverso nivel y época, barrancas, arroyos y la cartelería de la Rutacalle principal, permiten diferenciar entre los balnearios.

Esta expansión, se ha destacado como ejemplo de gran transformación desnaturalizadora, lenta y persistente, y no tanto por la edificación. Ilustres ciudadanos resolvieron y se aceptó de buen grado, forestar para fijar las dunas



Plano Montevideo 1920. Fuento: Archivo ITU 


\section{ID_INVESTIGACIONES}

con pinos, eucaliptos y otras especies exóticas, en proceso de aculturación ${ }^{13} a$ gran escala, para permitir el fraccionamiento de estancias improductivas en suelo arenoso. En el proceso algunas poblaciones surgidas en torno a las estaciones de tren, se extendieron hacia y/o por la costa, y adoptaron por obra de Sociedades promotoras el carácter de pequeñas estaciones balnearias. Potenciadas por los contingentes argentinos temporarios pero constantes, originaron infraestructuras y arquitecturas más cosmopolitas. Se destacan Atlántida y La Floresta, de cuadrículas y diagonales con rotondas, ramblas, árboles hoy añosos y diversas figuras antropizadas del paisaje, el bosque uruguayo contrapuesto a la Pampa al decir de Borges,J.L., que como otros intelectuales lo frecuentaban.

Más hacia el Océano, Piriápolis primero, luego Punta del Este y La Paloma son los más importantes ejemplos de ciudades o estaciones balnearias planificadas por empresarios como el mítico Piria ${ }^{14}$. Proyectos ambiciosos en sitios de interés relevante, bahía entre cerros, penínsulas-puertos y pesqueros con playas de ambas orientaciones. En las oceánicas, arquitectos formados en el urbanismo paisajista ${ }^{15}$ o lecorbuseriano proyectaron trazas y arbolados, aunque desvirtuados posteriormente y las obras residenciales modernistas reflejos del esplendor de los sectores más adinerados de ambas márgenes rioplatenses. Incorporan símbolos de la imagen de la Costa Azul mediterránea, y posteriormente de los otros centros de la arquitectura moderna, art decó y modern-style, con amplios jardines abiertos a la vía pública.

Desde el concepto de paisaje escénico intencionado respecto al potencial del territorio para la recreación en busca del reencuentro con la geografía, las

\footnotetext{
${ }^{13}$ Gilmet, H. (2001) en Arquitectura al Eje. Edit.Trilce. Mvdeo

${ }^{14}$ Francisco Piria (rematador en Montevideo y creador de Piriapolis) ha dado lugar a varias crónicas. Grompone, J. (1990) escritor-cientifico novela su extraordinaria historia en Hotel de Baños. Edit. Banda oriental

${ }_{15}^{\text {Oriental }}$ Gomez Gavazzo,C. primero y Scasso, A. posteriormente, realizaron diferentes Planes para La Paloma parcialmente ejecutados (1938 y década de 1950). Bonet, A. en Punta Ballena, alli y en la península de P. del Este Gomez Gavazzo.
} 


\section{ID_INVESTIGACIONES}

ciudades turísticas en lugares notables, destacan entre el conjunto de los fraccionamientos balnearios de arquitectura doméstica individual con jardines en calles sin pavimentar de terrenos planos. Pero interesa la modalidad del gran negocio de acción promotora de rematadores, agrimensores y fraccionadores, con la venta en cuotas de parcelas medianas durante varias décadas del siglo XX por su relación con los vacíos de Rocha. Con mínima inversión en infraestructuras, se nutrió del sueño de la segunda casa de balneario con nombres sugerentes respecto a sol, playa, pinares, que por mucho tiempo fueron sólo trazados y parcelarios con viviendas subutilizadas, semi-ajardinados. Paradójicamente esta acción empresarial, permitió en Canelones desde los años 70, atravesando sucesivas modificaciones familiares, éxodos y avatares el rápido cambio a suburbios. Manteniéndose el atractivo económico y cultural del modelo, se ocuparon rápidamente los numerosos predios vacíos a menores costos que en Montevideo. Se construyeron ex-profeso viviendas permanentes, para sectores medios y medios-altos, buscando el ideal de sol y playa a imagen del Oeste californiano, incluyendo el uso del automóvil privado. Devinieron mezcla híbrida de balnearios y barrios dormitorios, para los integrantes que trabajan de las familias y finalmente se unieron por la costa con una nueva Ruta, desconsiderando los criterios recomendables.

Al densificarse y convertirse en Ciudad de la Costa, se evidenciaron las fallas más graves del modelo, la falta de infraestructura de saneamiento estropeó la vialidad y las playas y obliga a costosa reparación ex-post. La utilización temporaria de viviendas, en bajas densidades no exigía redes de abastecimiento, evacuación, calles pavimentadas y equipamiento público, pero sí el barrio metropolitano. Al Norte de las primeras Rutas Interbalnearias, barrios con escasa urbanidad en gradiente decreciente de niveles sociales, completan la particular expansión urbana montevideana costera, diferente a las de los corredores Norte, y Noroeste más pobres y latinoamericanos. El gran 


\section{ID_INVESTIGACIONES}

stock construido y el mejoramiento constante de las comunicaciones hace improbable una vuelta atrás de la tendencia al uso para residencia permanente de estas urbanizaciones. Las nuevas de altísimo nivel cerca del Aeropuerto la consolidan, incluyendo barrios exclusivos con lagos y las pobres de Carrasco Norte son otro caso de intervención costosa ineludible. Tal como se previó, en el Plan de Ordenamiento territorial (POT 1998) la sociedad toda pagará el costo de una extensión urbana innecesaria e inconveniente.

En el Suroeste otro sector turístico relevante es Colonia Departamento con algunas pequeñas bahías-puertos naturales, barrancos, playas de arena y limo, borde de territorios costeros fértiles en producción agrícola y granjera, que está muy ligado históricamente a la gran capital porteña. Por cercanía cultural y económica; desde los materiales para su construcción (extraídos de este lado), las barcazas, los aliscafos y las modas, los unen. Su turismo de fin de semana incluye la navegación deportiva, el recorrido patrimonial y de descanso playero, muy accesible para bonaerenses, muchos con sus embarcaciones. Complementa el atractivo turístico hacia extranjeros de Bs.As y es disfrutable también por locales. La expresión parajes costeros, vinculada con la de paisajes culturales, referente a la oportunidad de incursiones y visualizaciones de corta duración, sin implicar construcciones e infraestructuras costosas, es interesante objeto de trabajos de la Maestría Manejo Costero Integrado Sur. (Olveyra,G; Perdomo, A., 2010).

Desde los bordes-balcones al río del casco portugués, Patrimonio Mundial Unesco, y de la Rambla de Colonia del Sacramento, que reflejan eclécticamente los modelos históricos adoptados, se atisba la gran ciudad que la pueblerina admira en relación contradictoria.

La presión inmobiliaria aquí ha sido persistente y últimamente con crecientes inversiones multinacionales, en la conversión hotelera. La escasa diversificación de alojamientos, siempre insuficiente, por su carácter concentra- 


\section{ID_INVESTIGACIONES}

do semanalmente se suma a los principales efectos producidos en casi todos los centros turísticos patrimoniales: la imposición de la imagen turísticocosmopolita, los servicios a esta demanda y las ganancias producidas, han desplazado totalmente a la población antigua, gentifricándolo y modificándolo en cuanto a propietarios, habitantes y usos. ${ }^{16}$ En conflictos permanentes, las Comisiones Especiales de Patrimonio, han colisionado con los intereses desarrolladores y sus defensores políticos. Aún pospuestos indefinidamente los Planes para el puente binacional, subsiste el conflicto latente, intrincado con los otros, la temida conversión en suburbio porteño de nuestras despobladas costas y pequeñas ciudades y la imposición de modalidades globales, que la versión televisiva porteña ridiculiza, no es aceptada por el pequeño país ¿conservador?.

El tramo costero de Colonia-San José, por no presentar particularidades geográficas de atractivo relevante, es utilizado para recreación local y de navegación limitada a las desembocaduras de las cuencas, accesos privilegiados a conjuntos de pueblos que así se generaron. ${ }^{17} \mathrm{Su}$ escasa población, habilita su protección en términos de prioridad productiva, y permite mantener su catastro rural, no fraccionable. En la cuenca del caudaloso Río Santa Lucía, límite con Montevideo, sus tierras fértiles y de humedales dan discontinuidad a la capital. A diferencia de la costa Este, el brazo metropolitano Ciudad del Plata en San José, muestra los más perniciosos efectos del asentamiento en hábitat autoconstruído por cercanía a fuentes de trabajo industriales, focos de contaminación que se suman a las insuficiencias de la infraestructura. Cuentan con más probabilidad de éxito los proyectos de paisaje cultural protegido río arriba (Medina 2005) y en el lado montevideano, para unir lo que aún son parajes costeros aislados. Proyectos y promoción de circuitos,

\footnotetext{
${ }^{16}$ Blixen, D. (2007) Tesis FCSSS - UDELAR “Colonia de puta a reina”
${ }^{17}$ Olivera, Mabel. (2005) Trabajos Equipo ITU y Taller Schelotto en Cuenca Arroyo Rosario en Seminario Alfa-Montevideo
} 


\section{ID_INVESTIGACIONES}

integrando establecimientos productivos y áreas de gran interés paisajístico e histórico, se han efectivizado. ${ }^{18}$

En el último tramo Este de la costa departamental de Canelones y en la de Maldonado, persisten los fraccionamientos balnearios de los años 50 y 60 , con menor consolidación, escasa ocupación edilicia y/o de población permanente, con el atractivo agregado de cercanos paisajes de serranía y posibilidades de caminatas, ecoturismo y similares. La identidad particular es la escasa población aún en verano y la tranquilidad para el descanso y contemplación del paisaje, arroyos de torrentes con piedras, caídas de agua e intervenciones culturales singulares. La ecuación costo-beneficio de los traslados, aún con los nuevos automóviles no ha producido saturación.

\section{PAISAJES Y PARAJES COSTEROS. CAMPO, CAMPO DUNAR Y MAR}

En el caso de Rocha el concepto tradicional de "paraje costero" es apropiado y utilizado en este texto, en referencia a lugares particulares, puntos especialmente identificables por ser de resguardo, oasis, miradores, estar intercalados en vacíos o en medios uniformes, de estancia relativamente corta. Allí donde el estar y el permanecer forman parte del movimiento, que fue característico de nuestros antepasados semi-nómades, de los pescadores y navegantes, de los migrantes y de muchos turistas. $Y$ que lo es especialmente para las generaciones actuales, producto de las facilidades de los transportes contemporáneos y de nuevos hábitos culturales. También se relaciona el término con la inclusión en itinerarios de recorridos, de puntos que aunque no muy notables de a uno, se pueden vincular en relatos de carácter histórico pa-

\footnotetext{
${ }^{18}$ Proyectos para MONTEVIDEO Oeste en Seminarios Montevideo 2003 y en CONDE, D coord...(2011)Manejo Costero integrado en Uruguay.Ocho ensayos interdisciplinarios . Caso de $\mathrm{MCl}$ sur Gen.2 cap.3 pag. $87-122$
} 


\section{ID_INVESTIGACIONES}

trimonial, natural y cultural, a efectuarse en diversas modos según los públicos.

A partir de los análisis anteriores se puede extraer algún porqué: la costa de Rocha, con carácter diríase sorprendente o curioso, presenta en extensos

tramos costeros a pocos kilómetros de Maldonado-Punta del Este, grandes vacíos y sobretodo ¿como posicionarse hacia propuestas a futuro? Fraccionados casi en la misma época de las vacas gordas, quedaron abandonados, con apenas algunas señales fantasmagóricas de su carácter, ya que sus propietarios, desconocidos, muchos argentinos o sucesores de argentinos, los olvidaron, no los ocupan ni pagan tributos catastrales. Se trazaron en planos engañosos, sobre extensos arenales, con sectores de cárcavas, dunas, cursos de agua y desniveles del terreno, vegetación escasa por exposición a vientos fuertes, en costas oceánicas de playas poco aptas para baños. En proceso al menos abusivo, cercano a $1950 \ldots$ en un lapso de 10 años se fraccionaran cientos de padrones rurales otrora dedicados a la ganadería extensiva. Así se crearon 140.000 lotes individuales de 540 metros cuadrados promedio, sin luz, agua, calles ni saneamiento (Catalurda, C.; Heide, D. 2004).

Algunos fueron o devinieron en propiedades estatales, sobretodo del Ministerio de Ganaderia, Agricultura y Pesca, otros son bordes improductivos de establecimientos agropecuarios. De muy difícil accesibilidad, escasas construcciones, su abandono ha facilitado la generación de incendios forestales y tardíamente la activación eficaz de sistemas de emergencias y prevención. Las únicas urbanizaciones surgidas con proyectos de tales 0 , aprovechando situaciones paisajísticas particularmente atractivas, alrededor de faros para la navegación en aguas procelosas, con alguna característica de puerto natural son: el caso de la ciudad turística de La Paloma y el antiguo poblado de La Pedrera. Ambas muy próximas a la capital departamental, con población esta-

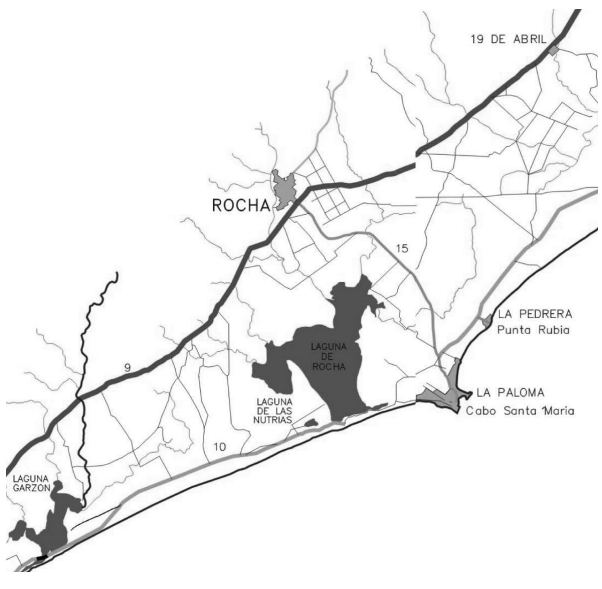

Sector Lagunas Garzón y Rocha-La Pedrera. Fuente Intendencia de Rocha 


\section{ID_INVESTIGACIONES}

ble escasa, aproximadamente igual número de viviendas que de habitantes, alojan parte de la presencia semi-residente de extranjeros en busca de calidades de vida especialmente relacionadas a la naturaleza. La mayoría de los trabajadores de mantenimiento y servicios, habitan en Rocha y alternan zafralmente trabajos rurales, manteniéndose viviendas cerradas por meses.

El fenómeno nuevo es que estos balnearios explotan en enero, con algunas características similares a Punta del Este, en cuanto al tipo de actividades nocturnas, no sólo de sol y playa. Albergan población juvenil de varios sectores sociales y procedencias, que muy asiduamente se traslada entre los poblados rochenses, por eventos musicales, o sociales, presencia de vientos y olas para surfear, competencias náuticas u otras. En temporadas, además de las casas veraniegas, se instalan locales permanentes o circunstanciales para eventos del bullicio juvenil. Cambiando de localización según razones comerciales u otras, promoviendo y fomentando los nomadismos a que nos referimos, dificultando planificaciones, indican la ventaja de su integración como paisajes culturales efímeros. La existencia desde hace décadas de camping municipales, o informales en sectores libres arbolados, y últimamente privados formales, les proporciona también el carácter relativamente inclusivo, revelador de la importancia de los sectores medios rioplatenses.

Estas urbanizaciones, con vegetación forestada similar a Canelones, de pinos marítimos, eucaliptos, acacias y tamarices, han permanecido aisladas muchas décadas, y es reciente su extensión. Surgidas en zonas apenas roturadas, de dunas móviles litoralmente activas paralelas o transversales, suelos con desniveles, cárcavas, sangrados de humedales, últimamente empiezan a soportar tensiones densificadoras y especulativas. En estas extensiones, arquitectos innovadores han afincado arquitecturas para público de dichas características, surgiendo otras tipologías además de la de vivienda chalet aislada o individual: conjuntos de cabañas, edificios de dos o tres niveles, mayor factor de ocupación en predios más grandes que los de las urbanizacio- 


\section{ID_INVESTIGACIONES}

nes de los 50-60. Las más visibles y legales alternan con construcciones ilegales, en cuanto a propiedad de los terrenos, o permisos de construcción. La normativa de edificación generalmente es discutible por su permisividad en alterar perfiles visuales y escaso su control. $Y$ aunque aparecen algunas residencias espectaculares $u$ ostentosas, más que nada por desniveles alardeados, son mayormente propias de arquitectos o de algunos promotores medianos. ${ }^{19}$ La conversión en Ruta 10 , de un antiguo camino costero, aunque apenas acondicionado ha extendido rápidamente los balnearios entre La Paloma y La Pedrera. Los fraccionamientos de La Aguada, Costa Azul, Antoniópolis, Santa Isabel, Punta Rubia, no eran hasta hace veinte años más que denominaciones de playas.

\section{6. ÁREAS Y PAISAJES PROTEGIDOS}

Esta extensa área, parte del ecosistema lacustre, que va desde Maldonado al Este, prolongándose en el litoral de Río Grande de Brasil, presenta varios episodios. Los primeros, muy antropizados han sido absorbidos por la urbanización de Maldonado-Punta del Este -Lagunas del Sauce y del Diario- y la Laguna Garzón, límite con el departamento de Rocha. Se relacionan con cursos interiores, depositarios de agua dulces, con el Océano Atlántico formando barras dunares de lagunas y arroyos muy dinámicas, que se abren y cierran por períodos más o menos cíclicos, y actúan como desovaderos de especies de moluscos, peces, tortugas. Extensas playas abiertas al fuerte oleaje y arena muy fina, los paisajes más agrestes han propiciado un tipo de turismo de bajísima intensidad, diferente al del balneario tradicional uruguayo, más bien de "parajes, camping informal, pesquería de recreo y artesanal, caminatas e incursiones cortas". Las lagunas ya mencionadas, así como las de

\footnotetext{
${ }^{19}$ Declaraciones ministeriales de prensa... "las únicas inversiones importantes en Uruguay, ... se concentran en Maldonado-Punta del Este ... -además de Montevideo- y parte significativa de éstas proviene de lavado de dinero a nivel internacional".
} 


\section{ID_INVESTIGACIONES}

Castillos, Laguna Negra y otras menores cercanas a Aguas Dulces, generan ambientes singulares muy propicios a la existencia de aves y otras especies en estado natural. La vegetación nativa y de palmares no ha sido mayormente modificada, salvo algunos sectores de parques, por lo cual esta extensa zona ha sido declarada de "Reserva de Biosfera"20. Prevista como lugar de avistamiento y paseos guiados restringidos, de acuerdo con los alcances de protección activa propuestos en las normas internacionales, la Convención ha tenido poca difusión y aplicación práctica. Organizaciones ambientalistas ${ }^{21}$ participan en su defensa y promoción, y también cuestionan varias disposiciones.

La Ordenanza Costera de Rocha de 2003, las sucesivas de 2006 y sus actualizaciones, con similar asesoramiento y apoyo de cooperación internacional prevén planes especiales para diversos sectores y proyectos concertados. Fue recibida con expectativas y se interpretaba que alentaría modalidades respetuosas del interés colectivo y los ambientes caracterizados para Centros Poblados y vacíos (de gente asentada) con criterio inclusivo. En la primer versión, se enunciaba procurar evitar los peores impactos urbanizadores, incorporando los sectores muy amenazados al SNAP (Sistema Nacional de Áreas Protegidas) y concentrando desarrollos urbanos. Se percibió un cambio de paradigma: aquello que antes se entendía como atraso en el desarrollo económico de la región, se transformaría en una característica única atractora de otro tipo de beneficios. Según estas disposiciones, se ha dividido la zona costera al Sur de la Ruta 10 en tramos, entre la laguna Garzón y la Laguna de Rocha al borde del par La Paloma- Rocha ciudad, se aplicaría el reciente Plan Parcial de las Lagunas. Por su intermedio, se autorizan modificaciones normativas y venta de antiguos fraccionamientos deshabitados cercanos a la Laguna de Rocha, que ha sido incorporada como Paisaje Prote-

${ }^{20}$ Probides entidad para Protección de la Biosfera (RAMSAR)incluye Universidad y Cooperación Europea la asignó

${ }^{21}$ Ver en Conde,D. y otros, (2009) .Compilacion publicada por ONG Vida Silvestre

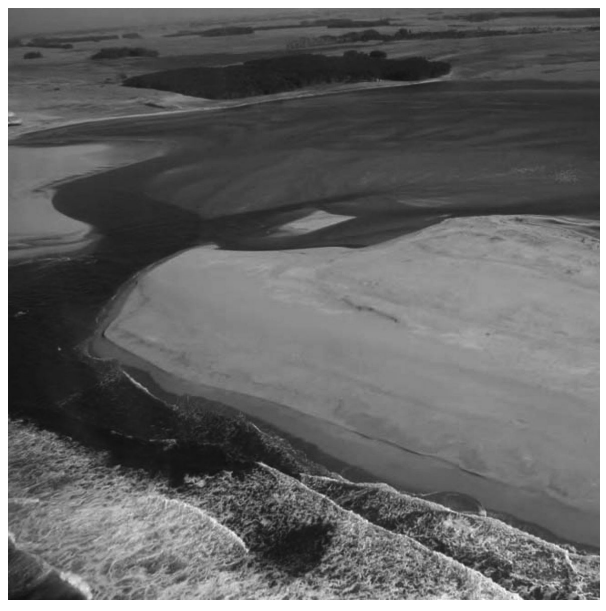

Barra Laguna de Rocha. Fuente Intendencia de Rocha 


\section{ID_INVESTIGACIONES}

gido al Sistema Nacional SNAP ${ }^{22}$. Se ha señalado certeramente, en la puesta de manifiesto pública y desde ámbitos académicos y sociales, cuán peligroso sería el acercamiento urbanizador, desvirtuando dicho carácter.

En estudios recientes sobre la faja costera Atlántica y cercanías de dicha laguna en Playa Solari de La Paloma, (Gadino, I. 2010) se ponen en evidencia las hipótesis manejadas por docentes de la Facultad de Ciencias. Los efectos de la forestación y el fraccionamiento en desmedro del campo dunar; de variaciones relacionables de éste, el humedal y la pradera, quitando espacio principalmente al herbazal psamófilo y de la playa, en su capacidad de absorción en un período relativamente corto. $Y$ analizando la inconveniencia de consolidar aquellos fraccionamientos antiguos que no han prosperado, por: los valores ambientales y paisajísticos que poseen los entornos de la laguna de Rocha, que hacen que la zona pueda ser considerada un área de oportunidad que promueva el desarrollo de la actividad turística de manera compatible con la conservación de los recursos. El Plan Parcial para las Lagunas es bastante incoherente con las anteriores declaraciones y documentos y especialmente porque se presenta casi al mismo tiempo que el proyecto de construcción de un puente en la barra de Laguna Garzón. Éste uniría el balneario seudo-rústico pero de gran prestigio y costosas residencias de José Ignacio en el Departamento de Maldonado, con los fraccionamientos antiguos apenas ocupados de Rocha, en el tramo que va hasta la Laguna homónima. $Y$ nos interpela directamente sobre el o los sentidos y características del futuro turístico costero en esta zona.

Podría afirmarse que la esencia del conflicto radica en la escasa valoración y educación ambiental respecto a estos territorios y recursos por parte de la población urbana, los productores, técnicos y autoridades que fuimos formados en los paradigmas del progreso y el desarrollo productivo -infinitamente a

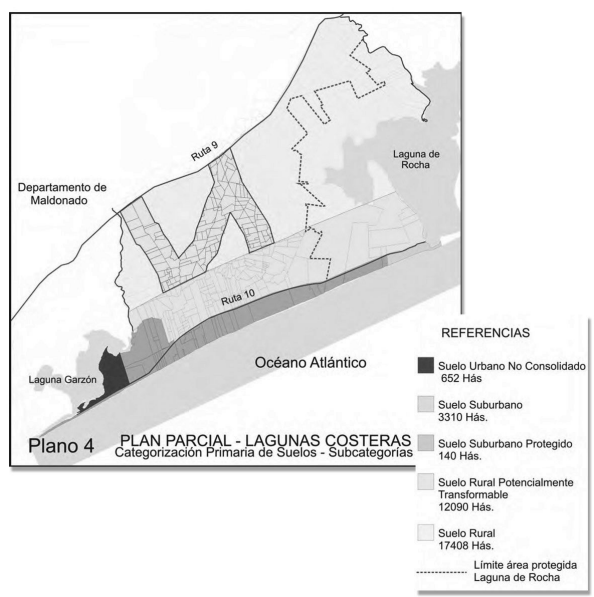

Plan Parcial Lagunas. Fuente: Intendencia de Rocha

\footnotetext{
${ }^{22}$ Op.cit.Idem
} 


\section{ID_INVESTIGACIONES}

disposición de los humanos-. La riqueza natural como bien colectivo y recurso ambiental preciado en si mismo, equilibrador de ecosistemas microregionales $\mathrm{y}$ del clima planetario, no es reconocido o aún está poco socializado. Las prácticas de décadas de gestiones no promotoras del control ni del desarrollo dejaron como legado, al no haber prosperado en Rocha las réplicas de los modelos turísticos esperados, el incumplimiento tributario. A posteriori, por el desfinanciamiento histórico e ilógico de comuna tan rica, pretende mostrarse beneficioso el impulsar modalidades de ocupación y usos que le aseguren rentabilidad. Las que surgen como posibles en las nuevas normativas, atendiendo al interés y presión de promotores, son chacras marítimas, clubes de campo y hotelería de alto nivel, que redundarían en acciones segregativas y privatizadoras del espacio, tal como en la mayor parte del mundo, extranjerizando las costas. Es altamente probable, según los antecedentes conocidos, que los propietarios de parcelas grandes no aseguren la protección ambiental recomendada por las Convenciones internacionales y el conocimiento científico-ecológico actual. La sustitución del paisaje dunar, o campo dunar de la zona activa, de humedales o lacustre, por predios ajardinados o campos de golf con vegetación no autóctona, lagos o piscinas artificiales, aún sin acarrear los problemas extremos de la impermeabilización urbana, son negativas en áreas protegidas o de amortiguación.

La aprobación largamente esperada de Instrumentos legales, como la Ley de Ordenamiento Territorial y Desarrollo Sustentable LOTDS en 2008, además de necesarias precisiones, Directrices, Ordenanzas y Normativas aún en estudio, no suplen los estudios particularizados. Convertida la Intendencia comunal en importante propietaria u oferente por morosidad, según dichas disposiciones y la Ordenanza Costera, se aprecia un peligro latente. ¿Quien asegura que con fraccionamientos de este nuevo tipo cercanos a las barras entre mar y lagunas no serán modificadas sus condiciones, los arroyos no cambien su curso y con ellos su fauna y demás recursos ambientales, e incluso hasta las mismas pro- 


\section{ID_INVESTIGACIONES}

piedades y construcciones en peligro? ¿Es conveniente la implantación de nueva residencia semi-permanente de familias o viviendas subutilizadas, cuando la Paloma, Punta del Este, sectores de Maldonado, Canelones y Montevideo, tienen stocks y predios vacíos? ¿Podría considerarse oportuno este modelo, pero en algunos sectores con menor dinámica natural $\mathrm{y}$ poblacional y más controlables? ¿Por ejemplo, en predios forestados de propiedad fiscal, ya largamente anunciada su venta, entre Valizas y Aguas Dulces, daría lugar a la presencia de nuevos pobladores con intereses exclusivistas, diferentes a los actuales de dichos balnearios, como sucedió en Cabo Polonio y sucede en José Ignacio?

Difícilmente la Ley o la Ordenanza Costera de Rocha y sus Planes sean eficientes a la hora de limitar derechos de propiedad, Parte de las propuestas, pueden estar esbozadas en otras modalidades de apropiación y disfrute en esta zona, otras historias, aunque no exentas de efectos depredadores y fracasos, menos atadas a derechos individuales de promitentes o avezados especuladores o recientes propietarios.

\section{PARAJES COSTEROS E ITINERARIOS EN ROCHA}

Los que como tales permanecen, surgieron como pueblos de pesquería, vaquerías desde el mar o por naufragios, aislados y relacionados mínimamente con las ciudades próximas, Castillos y Rocha. En las últimas décadas, han sido unidos por caminatas de playa y actividades juveniles significativamente más intensas que las protagonizadas por los originarios pescadores de tiburón y otras especies. Fueron éstos, los preparadores de bacalao, que en incursiones por la costa desde el mar y por tierra, buscando mejores sitios, los crearon y cambiaron sus lugares de radicación en algunos casos. Uno de gran interés por su antigüedad, y vicisitudes es el poblado de la Barra del Arroyo Valizas, que estuvo en su margen Sur y cambió hacia la del Norte, manteniendo siempre su 


\section{ID_INVESTIGACIONES}

vado, atravesamiento y navegación, como actividad continua y la pesca como sustento.

Allí como en Aguas Dulces, Cabo Polonio y Punta del Diablo, con diferentes génesis y características surgieron pulperías y viviendas precarias en terrenos de dudosa propiedad y límites, por tanto considerados espacios colectivos. Durante mucho tiempo y hasta hace poco, sin demarcación predial y/o en fraccionamientos rurales recorribles y de radicación esporádica, por lo que los apellidos familiares se repiten. Por ser zonas de playas y roquedales muy peligrosas para la navegación cercana a la costa, tempranamente se construyó el Faro en el tómbolo de Cabo Polonio. Estuvo allí instalada la factoría lobera estatal, precisamente atraídos los animales, por esta particularidad. Asentados por largos períodos, el médico y los primeros proveedores de servicios al personal y a pescadores, resultaron también los primeros arqueólogos aficionados. Desde los años 70 , estos pueblos empiezan a convertirse en atractores de turismo juvenil, -en busca de espacios de libertad que escaseaban en la época-, aunque de ocupación temporaria y a escala muy pequeña comparada con las ciudades turísticas y balnearios. En estas poblaciones, aunque va desapareciendo, es curioso apreciar la convivencia de pescadores tradicionales y artesanos (ocupados en la construcción, el mantenimiento de avíos de pesca y al límite de supervivencia durante gran parte del año, en viviendas de escaso confort), convertirse en temporada en agentes inmobiliarios y proveedores de servicios a europeos, argentinos y brasileros, en ambientes cosmopolitas.

Las prácticas reseñadas en toda la costa uruguaya, debieron regirse por la Ley de Centros Poblados de los años 40 y las posteriores, pero han implicado diferencias o violaciones flagrantes a lo allí establecido: la Ribera como zona de dominio y uso público, una Faja de Exclusión de 150 metros (en donde no se admiten ramblas ni fraccionamientos ni construcciones de ningún tipo) y una Faja de Defensa de Costas, de 250 metros definida por el Código de Aguas.

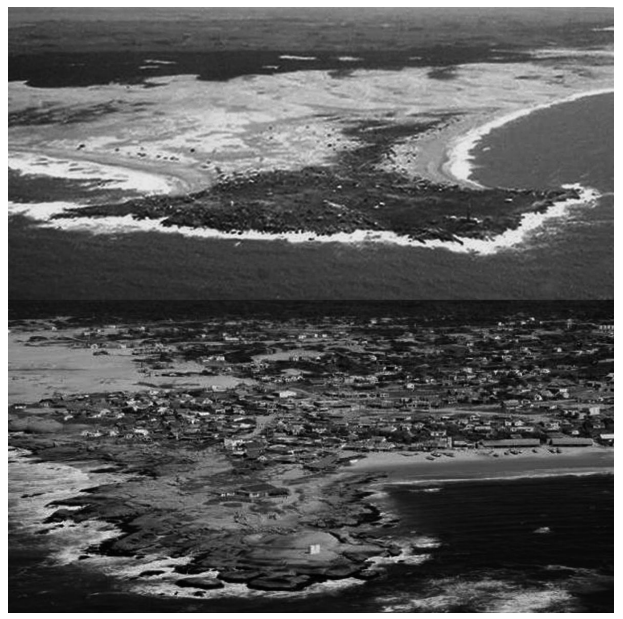

Punta del Diablo y Cabo Polonio Fuente: ID-Frontera 


\section{ID_INVESTIGACIONES}

Tampoco se ha aplicado lo definido como Zona de Interfase que comienza a partir de esta última, cuya finalidad es evitar la formación de pantallas arquitectónicas o acumulación de volúmenes, procurando una baja densidad de ocupación del suelo y asegurando la accesibilidad de la Ribera Marítima.

Normas no controladas donde era posible, menos en estos poblados, surgidos en generalizada -sino total- irregularidad, respecto a propiedad de la tierra y normativas existentes. Fueron afectados por prohibición de desarrollo desde la década del 90, cuando se crea el Ministerio de Vivienda, Ordenamiento Territorial y Medio Ambiente.

En el caso de Aguas Dulces y Valizas pasaron como parajes de propiedad del Ministerio a la Intendencia, para su ordenamiento en Plan a realizar, y posteriormente fueron denominados "Áreas de Desarrollo urbano turístico" por la Ordenanza Costera Departamental. En Cabo Polonio y Punta del Diablo, algunas edificaciones fueron objeto de demoliciones por inadecuación de su ubicación en playas, cordones dunares, zonas litorales activas. Sin embargo en éstos mismos parajes, se ha continuado edificando, multiplicando densidades, al menos hasta 2010 , sin control efectivo. Solamente han sido enfrentadas, ambos tipos de acciones, por propietarios-ocupantes con derechos creados en busca de exclusividad, que han logrado negociaciones convenientes con las autoridades o retomado juicios irresueltos por décadas. Múltiples acciones depredatorias por desconocimiento de la dinámica del sistema dunar durante muchos años, incluyendo tránsito de vehículos individual y empresarialmente organizados, y extensas forestaciones por parte del Estado, se intentan revertir en Cabo Polonio. Regularizar sus accesos, propiedad e incorporar a un nuevo régimen de protección, precipitado por una actual gran afluencia de público.

A las viejas y nuevas generaciones acostumbradas a indeterminaciones prediales, falta de servicios y a la colectivización y austeridad consecuentes, se han sumado actualmente, otros sectores de mucho mayor poder adquisitivo y 


\section{ID_INVESTIGACIONES}

hábitos diferentes. Desde otros balnearios de Maldonado o Rocha, atraídos por experiencias novedosas, en paisajes sin duda muy atractivos, nacionales y extranjeros, en incursiones cortas, paran o recalan en estos parajes. Ante fenómenos que algunos días son de masividad extrema, se socializaron y quedaron en evidencia las degradaciones de larga data, irreparables y potenciales, por lo que ya no hubo excusas para omisiones. Mientras la Intendencia negociaba sobre la propiedad y clasificación del suelo de Cabo Polonio, con la absurda pretensión de declararlo suburbano para recaudar, ya desactivada la lobería hace tiempo y convertida en mirador turístico informal, se decidió controlar los accesos, la disposición de residuos y camping casual, por iniciativa de los pobladores antiguos y de las autoridades. Algunas prohibiciones como las de ingreso de vehículos (salvo colectivos especiales de empresas o eventuales servicios), han limitado positivamente tiempos de permanencia de personas y tránsito inconveniente por dunas y playas, pero gran parte de los daños en el ecosistema dunar y el paisaje han sido provocados por la forestación practicada por el propio MGAP y son probablemente irreversibles. En 2011 se concretó el pasaje al SNAP como Parque protegido y se concursó un llamado para Equipo autor del Plan de Manejo, pero no se atisba la Audiencia pública.

En el tramo al Oeste de Cabo Polonio, se extienden grandes arenales desiertos, que pretendieron ser fraccionamientos como los descriptos, con algún acceso indicado y nominado y alguna construcción entre terrenos rurales en producción agropecuaria. Con playas costeras agrestes, sin penínsulas, bahías o alguna protección del viento, es el caso de Oceanía del Polonio cuyo hotel promocionado en publicaciones internacionales, es una construcción en medio de la nada -quizás su principal atractivo, pero omitido-. El tramo de Cabo Polonio a Valizas, integra un ecosistema dunar de gran valor escénico, único y rico en especies y restos arqueológicos de naufragios, por la escasa presencia humana, oficializado como Monumento Natural. Siendo un acceso histórica- 
ID_INVESTIGACIONES
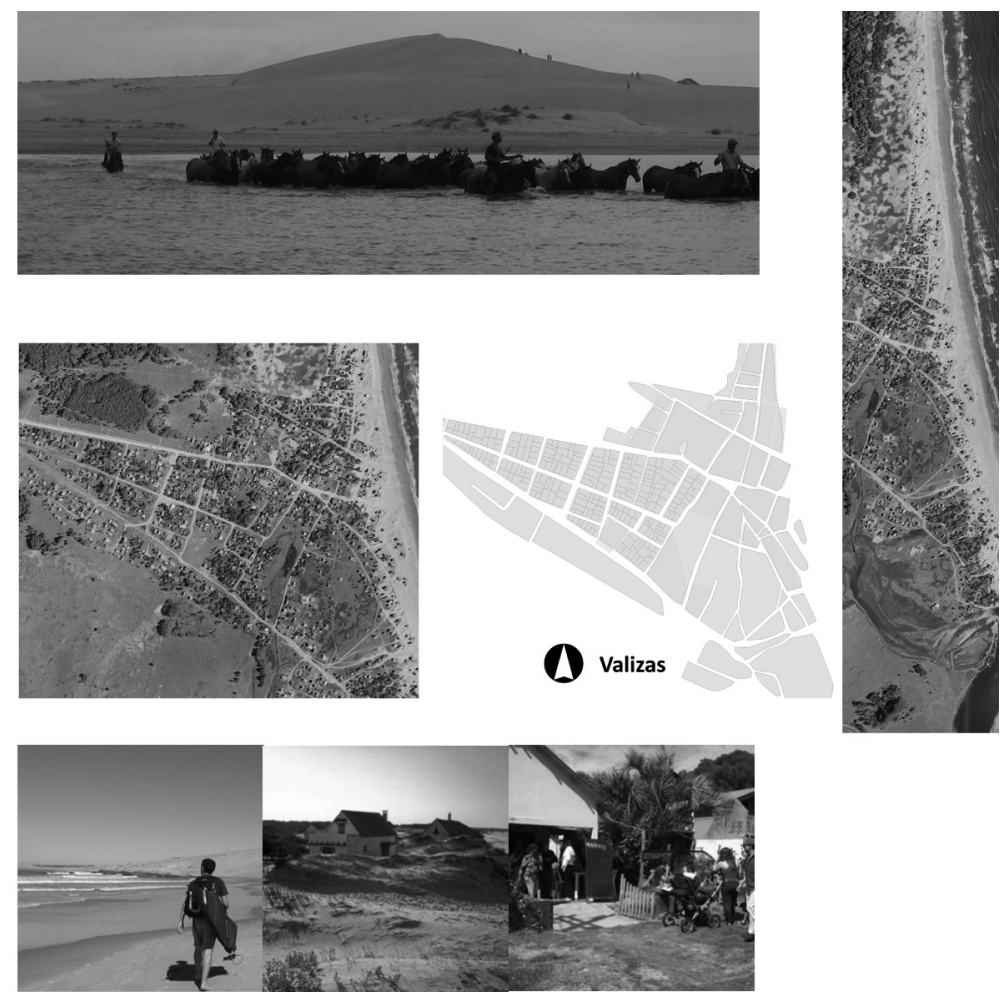

Valizas. Fuente: fotos Ingrid Roche y ortofotos de google

mente utilizado, a pie, carro y caballo, presenta algunas huellas históricoculturales, civilizatorias y míticas poco conocidas, muy factibles de integrarse a un itinerario turístico-patrimonial. Sectores juveniles reducidos, difundieron ahora más ampliamente y oficialmente por vía digital- los atractivos de las dunas monumentales, las islas de los Castillos, puntas rocosas, la verdadera Punta del Diablo, playas variadas, restos de naufragios y tormentas, marcas 


\section{ID_INVESTIGACIONES}

fronterizas antiguas, leyendas y últimamente miradores de avistamiento de ballenas, de buen diseño e intención, pero mantenimiento improbable.

Presentados en esta breve descripción algunos casos y características de poblados costeros, se pretende destacar el gran potencial en cuanto a modalidades recreativas turísticas diferentes, al menos de similar sustentabilidad que la de los balnearios tradicionales. El Departamento de Rocha cuenta actualmente con 6 de las 11 áreas ingresadas o en proceso de ingreso al Sistema Nacional de Áreas Protegidas SNAP, todas ellas ubicadas en la zona de costa. Se ha intentado mostrar, describiendo el caso de Canelones, como cambios en situaciones existentes que alteren superficies territoriales considerables -más si son costeras-, y aunque parezcan positivas, provocan otros, generalmente indeseados. La introducción de suelo vegetado, merma o aumento de forestación influyen en la napa freática, ni que hablar de disposición de aguas negras en caso de densificación, requiriendo barométrica, más tránsito vehicular y similares.

Dado el escaso desarrollo urbano y edificatorio, la cuasi virginidad de kilómetros y kilómetros de arenales, puede ser objeto de grandes inversiones transformadoras, con efectos de aparente desarrollo o progreso para la zona. Los Planes existentes aún no desarrollan medidas proactivas de promoción de recursos patrimoniales y su manejo, salvo en las reducidas incorporadas a las áreas protegidas. Por el contrario se observa que las autoridades departamentales y nacionales están recibiendo con interés, iniciativas de explotaciones de tipo extractivo y logístico que afectarían la zona costera. Un puerto de aguas profundas para grandes tonelajes de productos, o el emprendimiento minero a cielo abierto en zona arrocera con ducto de extracción al Océano, pondrían en peligro los recursos turísticos. Varios ejemplos lo han producido en el pasado, - la modificación en la bahía de la 


\section{ID_INVESTIGACIONES}

Paloma y el canal Andreoni en La Coronilla- ${ }^{23}$ no serían propios de los conocimientos actuales.

Cabe reflexionar, respecto al abandono de predios por la venta a personas desconocedoras de muchos de estos terrenos y circunstancias en el pasado; que probablemente la sorpresa al confirmar la irrealidad de lo que creyeron eran buenas inversiones, más el agravante de dificultades políticas binacionales en los años 50 para el traslado de turistas argentinos no se produzca. Sin embargo, aquella imposibilidad de ocuparlos y construir sus casas en los balnearios que soñaron, nos interroga sobre cual sería la demanda efectiva para impulsar emprendimientos exitosos, la duda sobre el origen y sostenibilidad de supuestas inversiones se hace mayor en la crisis de 2011. Caracterizados por identidades morfológicas, de interés paisajístico y formas culturales, de vida y de accesibilidad para sectores sociales diferentes, los poblados costeros, indudablemente se pueden valorizar y ordenar a futuro, reduciendo riesgos de uniformización, degradación y sobreexplotación de recursos. El departamento al Noroeste de la Ruta 9 principal al Brasil, también presenta interesantes atractivos histórico-arqueológicos, lugares de paisaje protegido, relictos naturales de fauna y flora, recorribles fácilmente al instaurar itinerarios visibles. Podrían así disminuirse las presiones sobre los ecosistemas costeros más frágiles, aunque continuaran siendo su principal atractivo y aumentando el ciclo de temporalidad anual para el disfrute y el ingreso turístico. Los instrumentos de aplicación deducibles del texto de la Ordenanza, sugerían esta consolidación de los poblados existentes y desde ellos, mejorados, la programación de itinerarios, incluyendo trayectos de serranías, palmares, zonas para caminatas en la costa, lagunas y el interior del territorio.

En el caso de Barra de Valizas, recorridos programados o semilibres, guiados por habitantes locales y anunciados en centros de acogida turística apoyados

${ }^{23}$ De Alava, D. articulo en op.cit. se refiere al Canal Andreoni, que destruyó Playa La Coronilla, una de las más prestigiosas en los $60 \mathrm{~s}$, para desagüe de las arroceras. 


\section{ID_INVESTIGACIONES}

por la municipalidad (ejemplo del Punto $G$ con museo, cyber, centro informativo) se han organizado. La formación de jóvenes oriundos en dichas actividades, el relevamiento y posible réplica o mejoramiento de alojamientos de hostales, bed and breakfast, albergues colectivos, supliendo hotelería y servicios turísticos casi inexistentes (por la baja rentabilidad que su carácter estacionario y el del público juvenil recibido), se atisbaba como futuro cercano en actividad universitaria con vecinos. ${ }^{24}$ Ya existen paseos en cabalgatas a las lagunas protegidas declarativamente, a los montes naturales de ombúes por el arroyo, a los manantiales de Castillos, donde se aprovisionaban los barcos. Falta popularizar la Historia del naufragio del Barco Leopoldina Rosa de 1842 al que se homenajea en la Plaza de Valizas sin explicación visible y las exposiciones en que varios arquitectos-fotógrafos, han documentado los cambios dinámicos del paisaje y de las construcciones originales en junco, totora y troncos, que resisten mejor que las rígidas los riesgos. En general, debieran acordarse y sumarse al mantenimiento o pasaje al status de áreas de Manejo público de mayor interés a proteger, las identidades inmateriales o perdurables en el recuerdo. La promoción de la inclusión de estos aspectos, relacionados al concepto de Paisajes Culturales y Turismo de Parajes Costeros, en propuestas que apoyen iniciativas locales privadas o parciales, no nos exime por su inseparabilidad profesional, de la crítica constructiva a los Planes y políticas públicas. Tampoco éstas han sido suficientemente socializadas y el debate se está produciendo, con las dificultades que gestiones de nuevo tipo conllevan.

En documentos de estudio de las Directrices Nacionales Costeras, previstas en la reciente Ley de Ordenamiento Territorial (LOTDS, 2008). La valoración que históricamente le han otorgado sus habitantes estables y ocasionales, ha ido creando paisajes culturales costeros particulares, pero con alto potencial de

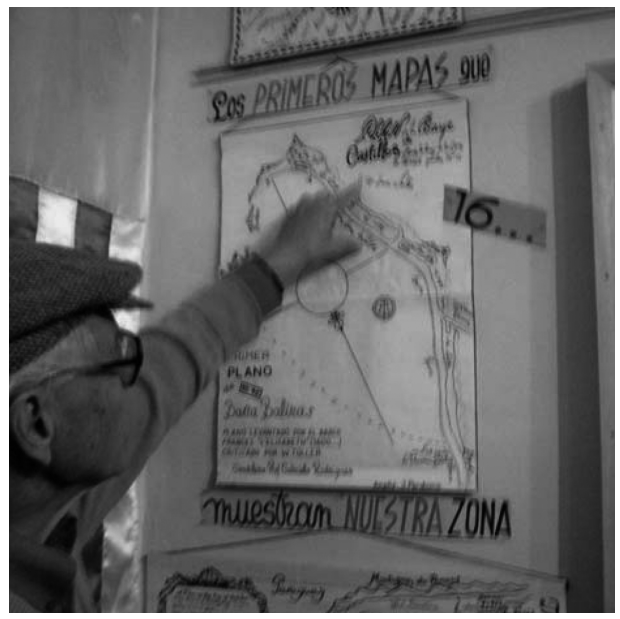

Profesor explicando Mapa en Taller: Fuente $\mathrm{MCl}$

${ }^{24}$ En Conde, D coord.(.2011) Manejo Costero integrado en Uruguay, cap.8 pag 248-277 se presenta el
Taller organizado por Equipo MCl $1^{\text {a }}$ generacion Caso Valizas 2009. Entrevistas a Prof J. Perdomo en Taller organizado por Equipo
Castillos y otros testimonios. 


\section{ID_INVESTIGACIONES}

modificación a futuro (Rocha presupuesto período 2006) o el modelo departamental de desarrollo turístico respetará y defenderá la identidad local, sus raíces históricas y sus recursos naturales. Se promoverá la singularidad de nuestro territorio departamental, como potenciador diferencial del turismo de naturaleza y como elemento de desarrollo económico local.

Lo cierto es que la propuesta de autorización de re-fraccionamientos de alto nivel como alternativa al modelo fracasado del balneario, a instancias de grandes promotores extranjeros ha tenido el efecto inmediato del aumento en el valor de las propiedades a niveles especulativos impresionantes. Este problema sustantivo a enfocar en las costas oceánicas, respecto a los precios y a los cambios normativos que se puedan estar gestando por presiones reales o previsibles de inversores internacionalizados con grandes capitales, hace necesaria la discusión de nuevos modelos. Además, sin entrar en aspectos legales o de procedimiento más que dudosos, ya han surgido iniciativas de este tipo y las propuestas que podrían sustituirlas o al menos reducir su costo social, democratizando el acceso y complementando con políticas turísticas proactivas, demoran en aparecer. Tampoco han resultado auspiciosos los criterios aplicados en el antiguo poblado de pescadores de Punta del Diablo. En paraje de enorme calidad escénica se han derribado construcciones con carácter propio (¿por pobres?) y permitido la densificación, sin planificación de vertidos pluviales y sanitarios Conviven vehículos, peatones y barcas en la zona de playa en extraño híbrido, mientras las arenas se van perdiendo, así como el carácter rústico y de palafitos de las construcciones, que a instancias de diseñadores novedosos van cambiando totalmente su aspecto. E desconocimiento social del Plan, concursado y ganado por profesionales prestigiosos, no permite dilucidar de donde parte la "confusión" por la que se permiten edificios de varios pisos en este contexto.

En los balnearios Aguas Dulces y Valizas, los Planes de regularización se han aplicado casi por omisión, a sabiendas de que fueron inconsultos, dejando que 


\section{ID_INVESTIGACIONES}

las construcciones sean destruídas por los elementos naturales, reconstruídas o suplidas casi sin control. Los residentes y turistas constantes, protegen sus viviendas con procedimientos en general ineficientes o inadecuados, sin asesoramiento ni penalización, también los palafitos originales van desapareciendo, pese a sus ventajas respecto a otros sistemas de estabilización. En el caso de Barra de Valizas, de historia del poblado relacionada con la dinámica y barra del arroyo homónimo, y el humedal en que se asienta, con las enormes dunas en su paisaje constitutivo, las intervenciones de la administración no han sido en general muy cuidadosas ambientalmente. Las aperturas artificiales de la barra, empujadas por los perjudicados por las inundaciones de los campos y los propios pescadores, plantean interrogantes sobre sus consecuencias, que no se han estudiado, habiéndose desecado el bañado-humedal y canalizado. La pavimentación y estacionamientos efectuados cercanos a la playa, no son apropiados a la protección de la primera faja dunar, afortunadamente la revisión del diseño del alumbrado ante protestas generalizadas, resulto adecuada.

Aún en el contexto de los aspectos negativos señalados, varios emprendimientos turísticos, descubrimientos paisajísticos incorporados a itinerarios, propuestas interesantes, han surgido en el área. Afortunadamente, dado que la afluencia turística se incrementa año a año, no ha logrado eliminarse el carácter específico de primacía de la presencia de la naturaleza en sus aspectos más agrestes y de las actividades humanas como subordinadas.

\section{CONCLUSIONES}

Se ha evidenciado que el alejamiento geográfico del país y de Rocha, respecto a los circuitos globales principales, tan presionados por la demanda de los grandes mercados del turismo masivo y/o de alto nivel, puede ser utilizado 


\section{ID_INVESTIGACIONES}

como ventaja comparativa para incentivar otros tipos de actividades recreativoresidenciales. En este caso, las tempranas figuras e instrumentos previstos en la Ordenanza prometían un gran avance exploratorio de nuevas tendencias, sin embargo hasta ahora no se ha avanzado más que en el sentido de lograr trabajosamente documentar el catastro y mediante re-clasificación de suelo y re-fraccionamientos lograr tributación para salir de crisis financieras agudas y el consiguiente descontrol en la gestión. Su aplicación con figuras nuevas de diverso tipo y clasificación, ideada sensatamente como proceso, es lenta. Denominaciones incorrectas como poblados consolidados, balnearios en desarrollo o similares y particularmente el uso del antiguo y perimido término suburbano, han generado polémicas y acciones judiciales. Estos extensos tramos de costas, cuasi completamente deshabitados, pero crecientemente visitados admiten ensayar modelos de desarrollo alternativos.

Es de esperar que las experiencias en desarrollo de gestión coparticipada en el Sistema de Áreas Naturales Protegidas, apenas implementado en Cabo Polonio y la consideración de Conjuntos Patrimoniales, o de valor histórico o natural relevante en Zonas isleñas, aportarán al instrumental del ordenamiento territorial y a la promoción de modalidades de turismo cultural o alternativo en zonas donde los trabajadores alternan tareas de campo y de mar.

Aún con dificultades persistentes, existen buenas condiciones para adoptar políticas más respetuosas del ambiente y las identidades locales, impidiendo la urbanización continua y la masificación. Fomentando formas de turismo otras: microturismo informal y difuso como el de Montevideo Oeste, el de camping o similares, el característico de Rocha, el ecoturismo, de caminata, cabalgata o bicicleta, muy apreciados por una parte del turismo a atraer, el- juvenil europeo. Y que, interrelacionando mar y campo y los núcleos existentes entre sí, su capacidad de acogida y conexión con actividades y paisajes al interior del territorio, podrá evitarse la carga estacional intensa y la continuidad urbanizadora ribereña. En las áreas con dinámica dunar, lagunar $u$ otras, ya 


\section{ID_INVESTIGACIONES}

declaradas protegidas o a proteger como reservas y reductos de naturalidad y fragilidad, analizar modalidades de acceso público, integración y conocimiento posibles, en recorridos de interés exentos de los efectos adversos de ocupaciones intensivas.

La descripción detallada de elementos paisajísticos con diversos niveles de intervención humana o social, de interés histórico-cultural o arqueológico, que den cuenta e incluyan las realizaciones de los trabajadores anónimos: los paisajes culturales deben estar en la base de las directrices y normativas particulares, dotándolas de contenido intencionado. ${ }^{25}$

Por lo muy reciente de la aprobación de la Legislación ambiental y territorial actualizada, su aplicación normativa y efectiva apenas se inicia: las posibilidades de potenciar valores e identidades están abiertas. Estudios amplios y profundos en términos de unidades de paisaje, habilitarían el empleo de instrumentos proyectuales y de gestión tendientes a evitar la explotación masificada de recursos. Poner en valor las identidades es ordenar y proyectar el crecimiento para las generaciones futuras, avistando al desarrollo genuino a largo plazo, en el sentido de equilibrar los intereses de pobladores locales, visitantes, turistas constantes y proveedores de servicios y para el conjunto social.

\section{BIBLIOGRAFÍA DE REFERENCIA}

AUGE, M. (2007) El oficio del antropólogo. Editorial Gedisa, Barcelona BARRAN, J.P. (2008) Intimidad, Divorcio y Nueva Moral en Uruguay del 900. Editorial Banda Oriental. Montevideo.

CATALURDA, C ; HEIDE, D. (2004) Trabajo para Maestría MOTDU-FARQ- UdelaR.

\footnotetext{
${ }^{25}$ Instituto de Diseño, Facultad de Arquitectura. UdelaR 2010 La Frontera del Agua. Edición IMM, Junta
} de Andalucía, es un ejemplo pionero. 
ID_INVESTIGACIONES

GADINO, I. (2010) Playa Solari al Oeste de La Paloma. Trabajo para Maestría MA

Ciencias Ambientales.

HIERNAUX-NICOLAS, D. "Turismo e Imaginarios" en Cuaderno Ciencias Sociales,

Imaginarios Sociales y Turismo Sostenible. No. 123 FLACSO, San José- Costa Rica pp. 7-

36

Instituto de Historia-Farq, UdelaR - CESIO, L y PONTE, C. (2005 ) Ponencia en Terceras Jornadas de Historia Económica. "La dialéctica turismo /patrimonio en Uruguay"

Instituto de Teoría y Urbanismo ITU-Intendencia Maldonado.(2010) Talleres Maldonado.

MEDINA, M. (2005) Tesis MOTDU: Construir el futuro, revalorizando el pasado. El turismo cultural en el territorio metropolitano.

OLIVERA, O. (2007) Valizas y su entorno

OLVEYRA, G. y PERDOMO, A. 2010. blog www.

URRUZOLA, J.P. (2007) Contribución a la critica del territorio como materia ordenable.

Tesis MOTDU-MVOTMA

VARESE, J. A. (1998) De Naufragios y leyendas en la costa de Rocha. 1998

VIDART, D. (1997) La trama de la identidad nacional. To $1^{\circ}$ Indios, negros, gauchos. Ed.

Banda Oriental, Montevideo

VITANCURT y FAGETTI, comp. (1995) PROBIDES. Publicación Institucional 
ID_INVESTIGACIONES

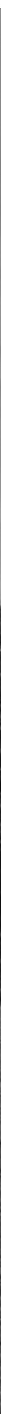

El Hervidero. Fuente: foto cedida por el Servicio de Medios Audiovisuales Facultad de Arquitectura, autora Andrea Sellanes 